Neurosurg Focus 24 (5):E4, 2008

\title{
Radiation therapy and CyberKnife radiosurgery in the management of craniopharyngiomas
}

\author{
Marco Lee, M.D., Ph.D., F.R.C.S., ${ }^{1}$ M. Yashar S. Kalani, Ph.D., ${ }^{1}$ \\ Samuel Cheshier, M.D., Ph.D., ${ }^{1}$ Iris C. Gibbs, M.D., John R. Adler JR., M.D., ${ }^{1}$ \\ and Steven D. Chang, M.D. ${ }^{1}$
}

Departments of ${ }^{\prime}$ Neurosurgery and ${ }^{2}$ Radiation Oncology, Stanford University School of Medicine, Stanford, California

\begin{abstract}
Object. Many benign intracranial tumors are amenable to radiotherapy treatment including meningiomas, schwannomas, pituitary tumors, and craniopharyngiomas. The authors present their experience in the treatment of craniopharyngiomas in 16 patients using frameless CyberKnife stereotactic radiosurgery (SRS). The authors discuss the role of radiation therapy in the management of these tumors, and more specifically, the role of CyberKnife SRS.

Methods. Sixteen patients were treated for residual or recurrent craniopharyngioma between 2000 and 2007 with CyberKnife SRS at Stanford University Medical Center. All patients underwent magnetic resonance imaging and visual and neuroendocrine evaluations before and at regular intervals after SRS. A multisession treatment regimen and a nonisocentric treatment plan for each patient were used with a mean marginal dose of 21.6 Gy and a mean maximal dose of 29.9 Gy.

Results. There were adequate clinical data to assess outcomes in 11 of 16 patients. Evaluation of patients between 13 and 71 years of age (mean 34.5 years) with a mean follow-up period of 15.4 months revealed no deterioration in visual or neuroendocrine function. Tumor shrinkage was achieved in 7 of these 11 patients, and tumor control in another 3. One patient had cystic enlargement of the residual tumor.

Conclusions. The authors' early experience with the application of CyberKnife SRS to residual or recurrent craniopharyngiomas has been positive; control or shrinkage of the tumor was achieved in $91 \%$ of patients, with no visual or neuroendocrine complications. Longer-term follow-up with a larger group of patients is required to fully evaluate the safety and effectiveness of this treatment modality. (DOI: $10.3171 /$ FOC/2008/24/5/E4)
\end{abstract}

\section{KEY WoRDS • benign tumor • craniopharyngioma • CyberKnife • fractionated stereotactic radiosurgery $\bullet$ perioptic lesion}

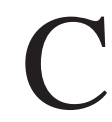

RANIOPHARYNGIOMAS are extraaxial epithelial tumors (World Health Organization Grade 1) that arise from remnants of the craniopharyngeal duct or Rathke pouch..$^{27}$ These are relatively uncommon tumors, accounting for not more than 5\% of all intracranial tumors, or up to $10 \%$ of brain tumors in children. The incidence of craniopharyngioma has been estimated at $\sim 1.5$ cases per million people per year, ${ }^{4,16}$ but may be considerably higher among members of specific ethnic groups, such as Japanese children (5.25 per million) ${ }^{31}$ There is a bimodal age distribution for this lesion, with peak rates in children 5-14 years of age and in adults 50-74 years of age.

Management of craniopharyngiomas remains a challenge because of the location of this tumor and its intimate

\footnotetext{
Abbreviations used in this paper: $\mathrm{CT}=$ computed tomography; GTR = gross-total resection; $\mathrm{MR}=$ magnetic resonance; SRS = stereotactic radiosurgery; STR = subtotal resection.
}

relationship with surrounding eloquent structures such as the optic apparatus, the hypothalamus, the pituitary gland, and the carotid arteries. Patients frequently present with visual disturbances and endocrine deficiencies because of the lesion's proximity to these structures. Involvement of the third ventricle can also lead to signs and symptoms of raised intracranial pressure from obstructive hydrocephalus. The treatment strategies usually considered involve either GTR or limited resection followed by radiation therapy. Other important treatment strategies that may be appropriate include cyst drainage and chemotherapy with bleomycin.

The clinical state of the patient, the anatomy of the tumor, and the expertise of the surgeon determine the choice of treatment; often a multimodal approach is the most appropriate. Whichever strategy is considered must be balanced against the risk of harming the surrounding eloquent structures. If it can be safely performed with minimal risk to these structures, GTR remains the treatment of choice as 
this allows rapid decompression, minimizes the risk of recurrence, and provides a specimen for histological diagnosis. However, judgment of minimal risk is often not clear-cut. Some surgeons favor STR coupled with adjunctive therapy to achieve the same goals. ${ }^{6,10,19,20,22,24,47,48,55} \mathrm{Re}$ current craniopharyngiomas must be considered separately because repeated surgery is associated with a higher risk of complications and a lower cure rate. 5,10,12,14,35,53

Comparing surgical complication rates across different case series produces a variable picture. The authors of most of the recent large series report a total resection rate of $27-90 \% .{ }^{10,18,51,54}$ Reported surgical mortality rates vary from 1.1 to $3.9 \% .^{10,45,51,54}$ However, without doubt, recurrent tumors are associated with significantly higher risks and poorer outcome, with overall mortality rates of 10.5$40.6 \% .^{10,54}$ It is also difficult to compare complication rates between series. Pituitary dysfunction may occur in 50$100 \%$ of patients, the most common form being diabetes insipidus. Visual deterioration may occur in up to $50 \%$ of patients who undergo GTR.

\section{Radiation Therapy for Craniopharyngiomas}

Although resection may be the primary treatment modality initially, craniopharyngiomas are difficult to cure with surgery alone. It has long been established that radiation therapy is effective against craniopharyngiomas, ${ }^{30}$ and it has become a standard of treatment for residual or recurrent craniopharyngiomas. The results of most case series have shown that after STR, adjuvant radiotherapy allows greater tumor control and a better survival rate than surgery alone (40 vs 90\%, 10-year progression-free survival). ${ }^{15,17,40,41,46,52}$ The case for primary radiation therapy for recurrent craniopharyngiomas is even stronger in terms of lower risk and better outcome, with 10-year progression-free survival in $30 \%$ of surgical patients and in $90 \%$ of those who underwent radiosurgery. ${ }^{23-25,36}$

The main strategy for maximizing effectiveness and minimizing the damage caused by radiation therapy is to deliver the radiation accurately while sparing surrounding normal structures and to optimize the radiation dosing scheme. Various means of achieving this include conformal radiotherapy, intensity modulated radiotherapy, stereotactic radiotherapy, and SRS. Stereotactic intracavitary radiation with ${ }^{90} \mathrm{Y}$ or ${ }^{32} \mathrm{P}$ is also used, especially as a primary treatment of cystic tumors or as an adjuvant treatment after surgery or radiotherapy.

However, conventionally fractionated focal radiation therapy around the sellar and suprasellar region is also associated with risks similar to those of surgery. Both treatments can cause pituitary dysfunction (diabetes insipidus, panhypopituitarism, and hypogonadism), hypothalamic dysfunction (hypothalamic obesity and sleep disturbances), and visual and cognitive deterioration. Radiation therapy carries the additional risk of radiation-induced necrosis, secondary malignancies, and vasculopathy. The normal optic apparatus is particularly sensitive to radiation, and even with optimized dose and fractionation regimens, there is a 3\% risk of optic neuropathy. ${ }^{11,34,37}$ Delayed pituitary failure after regional radiation therapy has also been well described and may occur in 30-70\% of patients who receive conventional radiotherapy. ${ }^{2,9,33}$ Other complications include secondary malignancies ${ }^{3,42,49}$ and temporal lobe necrosis..$^{21,49}$

\section{Stereotactic Radiosurgery and Radiotherapy}

Stereotaxy in radiotherapy allows accurate localization of the lesion so that a radiation beam can be targeted to the lesion while sparing the surrounding structures. Most stereotactic systems can deliver a radiation beam to within $\sim 1 \mathrm{~mm}$ of the lesion. Such accuracy means that a very high dose of radiation can be given as a single delivery to obliterate the tumor (SRS). However, some of the controversy surrounding the application of radiation therapy to craniopharyngiomas relates to the optimal dosing so that risks to the optic apparatus and pituitary gland are minimized. Is a focal single fraction radiotherapy dose better than a fractionated dose in a situation where the optic apparatus or pituitary gland is close to the lesion? Conventional fractionated radiotherapy can also be delivered by stereotactic means (stereotactic radiotherapy), thereby combining the advantages of fractionation with the accuracy of radiosurgery. Long-term results are still needed to see if stereotactic radiotherapy will indeed decrease the risk of damage to the surrounding structures and improve functional outcome. ${ }^{26,43,44}$

Stereotactic radiosurgical treatment of craniopharyngiomas is typically limited to tumors $3 \mathrm{~cm}$ or smaller that are 3-5-mm away from the optic chiasm and nerves. The authors of several studies have reported safe and effective long-term results with the Gamma Knife in the treatment of craniopharyngiomas. ${ }^{7,28,44,50}$ The CyberKnife (Accuray, Inc.) consists of a miniature lightweight linear accelerator mounted on a robotic arm with 6 degrees of freedom of movement. This allows unobstructed access to the entire body, and a photon beam can be targeted with submillimetric accuracy. The device uses an image-guided control loop with target tracking capabilities that can adjust to patient movements, thus obviating the use of invasive frames to stabilize the patient. In the present study we report the first series of the treatment of residual craniopharyngiomas situated within $2 \mathrm{~mm}$ of the optic apparatus or pituitary gland.

\section{Clinical Materials and Methods}

Sixteen patients with confirmed, previously resected craniopharyngiomas underwent SRS with the CyberKnife at Stanford University Medical Center between November 2000 and November 2007 (Fig. 1). A retrospective review of these cases was undertaken by obtaining clinical information from an institutional review board-approved prospective database. Each patient was evaluated by the neuroendocrinologist and neuroophthalmologist before and after SRS. A multidisciplinary team of neurosurgeons, radiation oncologists, and neuroradiologists evaluated each patient for treatment eligibility. Informed consent was obtained from each patient before enrollment in this institutional review board-approved clinical study.

\section{Radiosurgical Treatment Planning}

The lesions in each patient were evaluated on 1-25-mm contiguous slice, high-resolution CT images, with and without contrast enhancement (Iohexol, $350 \mathrm{mg} / \mathrm{ml}$; Nycomed, Inc.) with either a GE Light Speed 8i or $16 i$ unit. In most cases, thin-section MR images were also obtained. The image data were transferred to the CyberKnife work- 

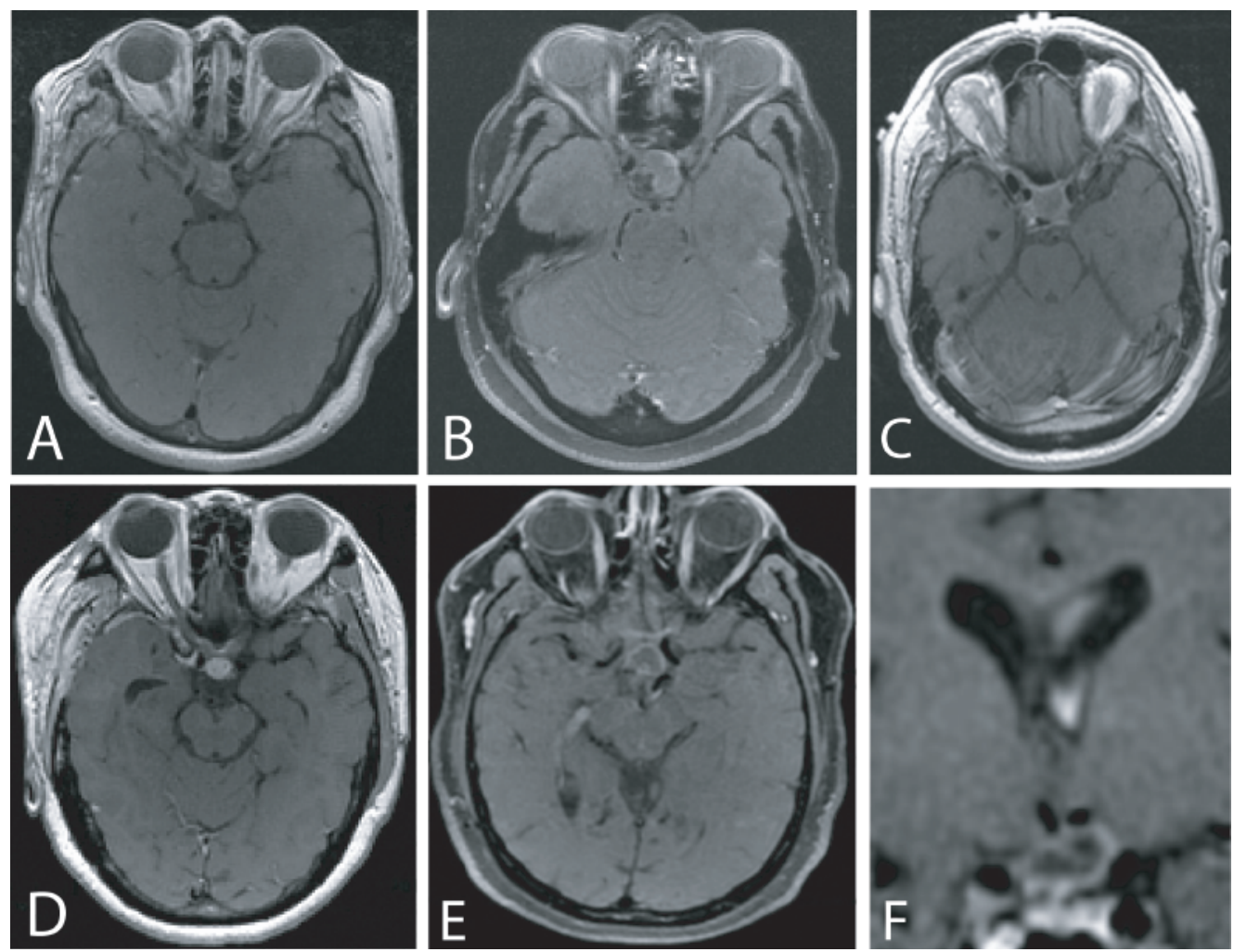

FIG. 1. A-E: Axial Gd-enhanced T1-weighted images obtained in the patients in Cases 16, 15, 10, 13, and 11, respectively. Residual or recurrent craniopharyngiomas prior to SRS are demonstrated. F: Coronal image obtained in the patient in Case 11.

station and the treating surgeon manually outlined the target volume and critical structures on the axial images using proprietary MultiPlan and InView software (Figs. 2 and 3). Simultaneous overlay of these contours on coronal and sagittal reconstructions was performed. In most cases, the noneffaced anterior visual pathways, including the optic nerves and chiasm, could be readily delineated, especially when an MR-CT fusion was performed. At times, however, portions of the optic apparatus could not be delineated with confidence because the tumor obscured or displaced a segment.

\section{Radiation Dose Selection}

In the present study, all treatment plans were designed using an inverse planning algorithm that involved setting dose constraints to minimize irradiation of specified structures such as the optic apparatus and maximize doses to the tumor. The neurosurgeon and radiation oncologist jointly determined the marginal and maximal doses, as well as the number of sessions. When delineation of the optic apparatus was clear, exposure to these critical structures was limited to $<5$ Gy per session. However, when the delineation of these structures was not clear, it was not possible to meet the exposure limit.

All patients received treatments in multiple sessions, ranging from 3 to 10 sessions, to a mean target volume of $6 \mathrm{~cm}^{3}$ (range $0.3-26.3 \mathrm{~cm}^{3}$ ), using a mean marginal dose of 21.6 Gy (range 18-38 Gy) prescribed to a mean isodose line of $75 \%$ (range $67-80 \%$ ). The mean maximum dose was 29.9 Gy (range 24.1-42.1 Gy).

\section{Treatment Delivery}

Patients were placed supine on the treatment couch and fitted with a previously constructed custom thermoplastic mask. Once the patient's position was registered, the radiation was delivered. After the completion of each session, patients received 4-8 $\mathrm{mg}$ of dexamethasone orally. The sessions were 12-24 hours apart.

\section{Evaluation of Patient Outcomes}

After SRS with the CyberKnife, all patients underwent clinical and radiological evaluation by a team consisting of neurosurgeons, radiation oncologists, neuroendocrinologists, neuroophthalmologists, and neuroradiologists. Magnetic resonance imaging and formal Goldman visual field assessments were performed at 6-month intervals for 2 years, then once every year. Patients who attended followup at outside institutions had their clinical reports, visual assessments, and imaging sent to us for review. The formula for an idealized ellipsoid (volume $=4 / 3 \pi$ (length $/ 2$ $\times$ width $/ 2 \times$ height $/ 2$ ) was used to estimate the tumor volume on pre- and posttreatment MR images.

\section{Results}

\section{Patient Characteristics}

Over an 8-year period, 16 patients were identified who had residual or recurrent craniopharyngiomas and were treated with CyberKnife radiosurgery. The patient characteristics are summarized in Table 1. Five of 16 patients 

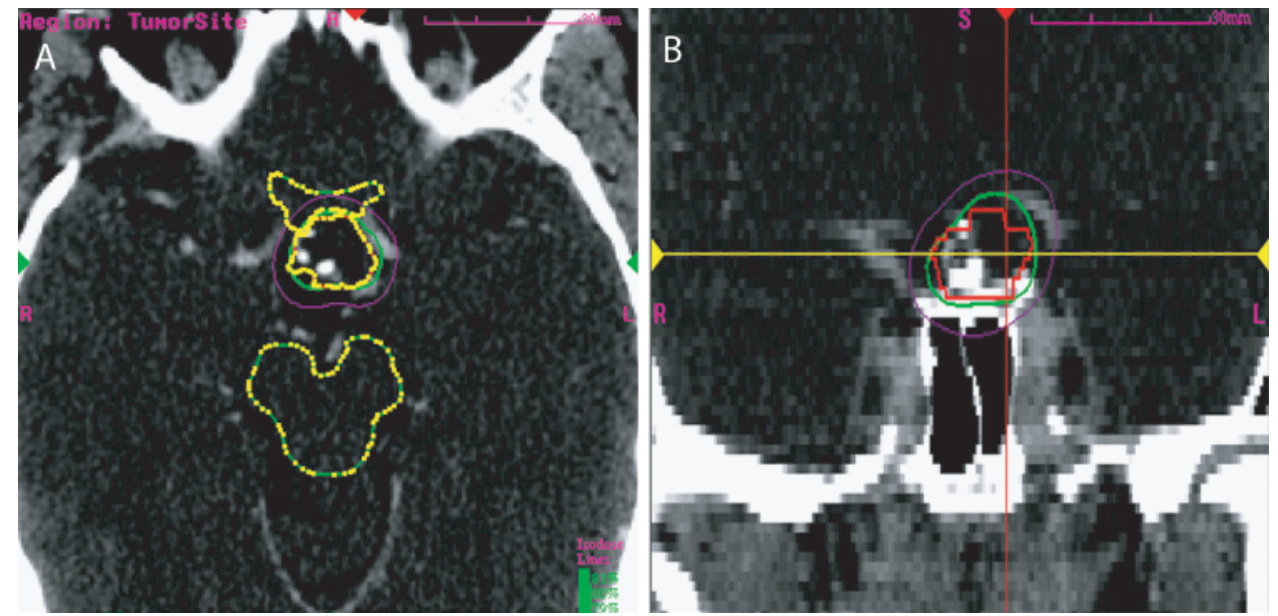

FIG. 2. Case 6. Axial CT scan (A) and coronal reconstruction (B). Dose planning with the CyberKnife treatment planning software. Tumor margin, optic nerves, chiasm, and tracts are delineated, and the radiation-sensitive optic apparatus is kept out of the high isodose areas. Red lines delineate tumor; yellow, vital structures; green, the $80 \%$ isodose; and purple, the $50 \%$ isodose.

(Cases 12-16) were excluded from the study either because of missing clinical data or insufficient follow-up. The mean age at treatment for the 11 included patients was 34.5 years (range 13-71 years). There were 5 men and 6 women. All patients initially presented with symptoms or signs attributable to the tumor. Ten of 11 had some degree of visual field loss. Only 1 patient (Case 7) did not experience visual disturbances. Five of 11 had endocrine abnormalities that required hormonal replacement. All patients underwent resection, and histological testing of the specimen confirmed the diagnosis of craniopharyngioma. Ten patients had operative reports documenting an STR with radiological confirmation. One patient underwent a complete resection, but follow-up MR images revealed a recurrence 1 year after surgery (Case 3 ). Four patients underwent 1 surgical procedure, 4 underwent 2 procedures, and 3 patients had 3 procedures. One patient received a 54-Gy dose of radiotherapy after the first surgery before presenting again 4 years later with worsening symptoms (Case 2). This patient underwent a second operation and then CyberKnife SRS.
In 9 patients, the symptoms improved after surgery, but 2 experienced worsened visual field deficits prior to SRS.

In most cases, the residual tumor was located in the suprasellar region, and in 10 cases it was found to be against or displacing the optic nerve or chiasm. The pituitary stalk alone was compressed in 1 patient.

\section{CyberKnife Treatment}

All patients had multisession CyberKnife SRS. Three patients had 3 sessions, 1 had 4 sessions, and 6 had 5 sessions. Due to the large size of the recurrent tumor and its proximity to critical structures, radiotherapy to 1 patient was administered over 10 sessions, which may be classified as stereotactic radiotherapy rather than radiosurgery. There were no acute complications in any of the patients.

\section{Treatment Outcomes}

The mean follow-up time was 15.4 months (range 4-64 months). All 10 patients with visual field or acuity prob-
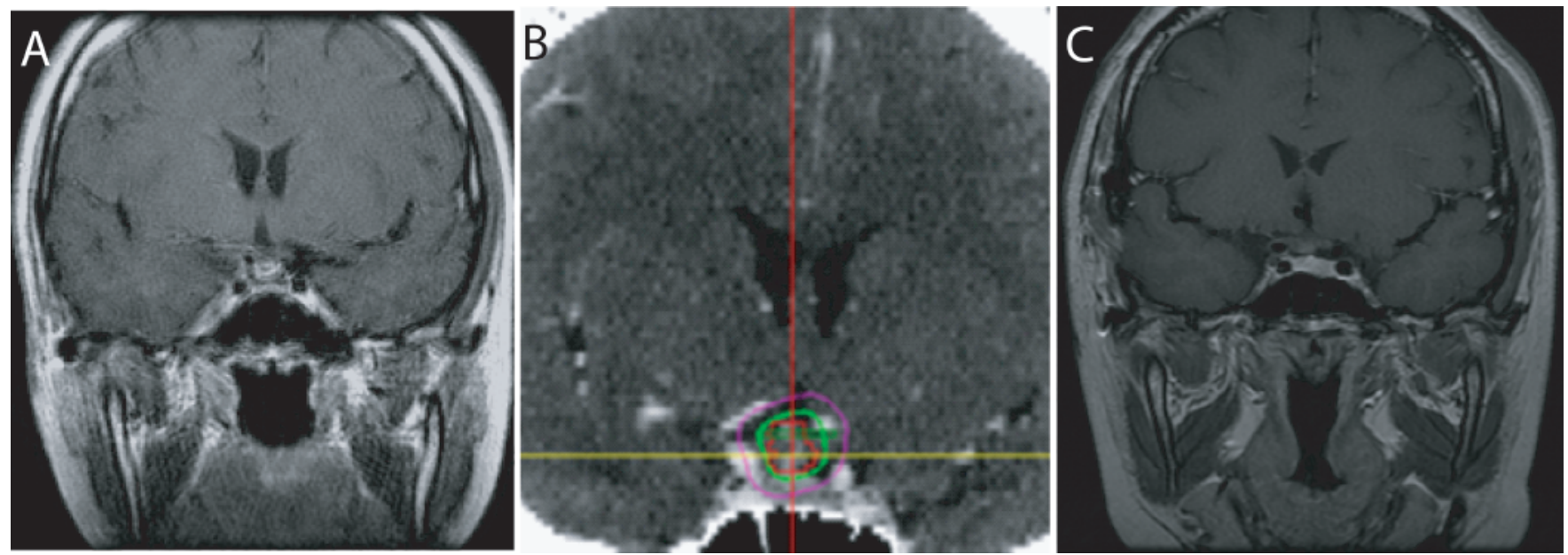

FIG. 3. Case 6. A: Image obtained preoperatively. B: Radiosurgical dose planning with thin-slice, high-resolution, contrast-enhanced CT. C: Image obtained 4 years after CyberKnife treatment. 
TABLE 1

Summary of characteristics of patients who underwent CyberKnife SRS for residual craniopharyngiomas, 2000-2007*

\begin{tabular}{|c|c|c|c|c|c|c|c|c|c|c|c|}
\hline $\begin{array}{l}\text { Case } \\
\text { No. }\end{array}$ & $\begin{array}{c}\text { Age } \\
\text { (yrs), Sex }\end{array}$ & Presentation & $\begin{array}{l}\text { No. } \\
\text { of } \\
\text { Ops }\end{array}$ & $\begin{array}{c}\text { Pre-SRS } \\
\text { Postop } \\
\text { RT }\end{array}$ & $\begin{array}{c}\text { Pre-SRS } \\
\text { Visual } \\
\text { Problems }\end{array}$ & $\begin{array}{l}\text { Endocrine } \\
\text { Problems }\end{array}$ & $\begin{array}{l}\text { No. of } \\
\text { Frac- } \\
\text { tions }\end{array}$ & $\begin{array}{l}\text { Treatment } \\
\text { Dose } \\
\text { (Gy) }\end{array}$ & $\begin{array}{c}\text { Mean } \\
\text { Isodose } \\
\text { Line }(\%)\end{array}$ & $\begin{array}{l}\text { Max } \\
\text { Dose } \\
(\mathrm{Gy})\end{array}$ & $\begin{array}{c}\text { Target } \\
\text { Volume } \\
\left(\mathrm{cm}^{3}\right)\end{array}$ \\
\hline 1 & $32, \mathrm{~F}$ & HA \& VFD & 3 & no & yes & no & 3 & 18 & 75 & 22.5 & 1.4 \\
\hline 2 & $16, \mathrm{~F}$ & HA \& VFD & 2 & yes & yes & no & 3 & 19.5 & 80 & 24.3 & 12.7 \\
\hline 3 & $71, \mathrm{M}$ & N\&V \& VFD & 1 & no & yes & no & 3 & 20 & 74 & 26.6 & 0.7 \\
\hline 4 & $45, \mathrm{~F}$ & hypopit \& VFD & 2 & no & yes & yes & 5 & 20 & 77 & 26 & 1.1 \\
\hline $5 \dagger$ & 43, M & hypopit \& VFD & 2 & no & yes & yes & 10 & 38 & 72 & 42.1 & 26.3 \\
\hline 6 & $17, \mathrm{~F}$ & HA, VFD & 1 & no & yes & no & 4 & 20 & 77 & 24.1 & 1.2 \\
\hline 7 & $13, \mathrm{~F}$ & WG \& hypopit & 3 & no & no & yes & 5 & 27.5 & 71 & 36.7 & 10.1 \\
\hline 8 & $20, \mathrm{M}$ & VFD \& hypopit & 1 & no & yes & yes & 5 & 25 & 76 & 30.5 & 0.3 \\
\hline 9 & $39, \mathrm{~F}$ & HA \& VFD & 2 & no & yes & no & 5 & 25 & 67 & 33.3 & 6.3 \\
\hline 10 & $37, \mathrm{M}$ & HA \& VFD & 3 & no & yes & no & 5 & 25 & 73 & 31.7 & 3.8 \\
\hline 11 & $46, \mathrm{M}$ & hypopit \& VFD & 1 & no & yes & yes & 5 & 25 & 80 & 31.3 & 1.3 \\
\hline 12 & $40, \mathrm{~F}$ & $\begin{array}{l}\text { incidental finding; } \\
\text { increased size } \\
\text { on imaging }\end{array}$ & 1 & no & no & no & 3 & 21 & 69 & 29.2 & 0.2 \\
\hline 13 & $49, \mathrm{~F}$ & $\begin{array}{l}\text { WG \& memory } \\
\text { problems }\end{array}$ & 1 & no & no & yes & 3 & 21 & 65 & 29.6 & 0.8 \\
\hline 14 & $66, \mathrm{M}$ & NA & 1 & no & no & no & 8 & 36 & 69 & 46.2 & 12.2 \\
\hline 15 & $43, \mathrm{~F}$ & HA \& VFD & 1 & no & no & yes & 5 & 27.5 & 77 & 35.7 & 2.3 \\
\hline 16 & $37, \mathrm{M}$ & $\begin{array}{l}\text { impotence \& } \\
\text { hypopit }\end{array}$ & 1 & no & no & yes & 5 & 27.5 & 70 & 39.3 & 5.6 \\
\hline
\end{tabular}

\footnotetext{
* The patients in Cases 12-16 were excluded from the analysis either due to missing clinical data or inadequate follow-up time. Abbrevations: $\mathrm{HA}=$ headache; hypopit = hypopituitarism; $\mathrm{NA}=$ not available; $\mathrm{N} \& \mathrm{~V}=$ nausea and vomiting; $\mathrm{RT}=$ radiation therapy; $\mathrm{VFD}=$ visual field deficit; $\mathrm{WG}=$ weight gain .

$\dagger$ This patient underwent stereotactic radiotherapy.
}

lems either improved or stayed the same after CyberKnife radiosurgery. There were no new neuroendocrine problems, and the 5 patients with endocrine problems remained stable with no new deterioration after CyberKnife treatment. Tumor shrinkage was seen in 7 patients, with 3 staying the same at 2 years posttreatment. In 1 patient, cystic enlargement of the residual tumor developed without any worsening signs or symptoms.

\section{Discussion}

The propensity of craniopharyngiomas to be closely associated with neurovascular structures of the parasellar region makes this benign tumor a neurosurgical challenge and far from "benign" for the patient. Often only STR is possible without causing further harm to the patient. The residual tumor is frequently stuck to or displaces the optic apparatus, pituitary gland, and other important parasellar structures. Because many patients will already have impaired vision, saving the residual visual function becomes even more important. Microsurgery has an important role in the rapid decompression of these critical structures, sometimes even offering the chance of a cure. However, leaving residual tumor around structures such as the optic nerves or chiasm is inevitable in many cases. Recurrent tumors and patients who are poor surgical candidates may also limit the role of surgery. The 2 main alternative treatments to surgery are single-session SRS or conventional fractionated radiotherapy.

Radiosurgery has proven to be very effective in many benign intracranial tumors. ${ }^{1}$ However, some studies have shown that injury to the optic nerve or chiasm may occur if $>8-10 \mathrm{~Gy}$ is delivered in a single fraction to a segment of the optic apparatus, ${ }^{13,32}$ while in another study craniopharyngiomas were successfully treated with a limit of 13 Gy to the optic apparatus. ${ }^{29}$ In general, however, radiosurgery is contraindicated if the distance between the tumor and optic apparatus is $<3 \mathrm{~mm}$ because the visual pathways would typically receive $>10 \mathrm{~Gy}$ is these situations.

In these perioptic lesions, the tradition has been to use conventional fractionated radiotherapy. Fractionation is a fundamental principle of radiation therapy and has biological advantages that allow recovery of normal adjacent tissue. Typically, benign lesions are treated with doses of 45-55 Gy in 1.8-2 Gy fractions to prevent growth of tumor and minimize injury to the visual pathways. Long-term (10 year) local tumor control ranges from 31 to $42 \%$ for patients treated with surgery alone compared with $57-89 \%$ in those treated with surgery and radiotherapy. ${ }^{15,17,39,41,46,52}$ However, there are limitations to its use, as the wide treatment field includes many structures including the optic apparatus, pituitary gland, hypothalamus, and medial temporal lobe that could all receive radiation. Subsequent injury to these structures, radiation necrosis, and secondary malignant changes can occasionally occur. The risk may only manifest itself after a long delay, but this is particularly important because benign conditions like craniopharyngiomas have good long-term survival prospects and many patients with these lesions are young. Another limitation is that when conventional radiotherapy fails, it almost inevitably precludes further radiotherapy treatment to the recurrent tumor. Finally, although of minor importance, conventional fractionated radiotherapy usually takes place over a 6-week course, which is less attractive to patients than other shorter treatment courses.

The tolerance of critical neurovascular structures to radi- 
ation depends on a multitude of factors including the amount of radiation received, the volume of tissue irradiated, and any prior injury or radiotherapy to the area. With the availability of image-guided radiosurgical technology, the principle of multisession delivery of radiosurgery can be incorporated with the anatomic precision and conformality of radiosurgery. This allows the precise delivery of lower and safer radiation doses than those used in singlesession radiosurgery, while at the same time exploiting the volume effect by applying higher and more effective doses than was possible with conventional radiation therapy. In this series, treatment plans were designed to keep the dose to the optic apparatus $<5$ Gy during any single session. The volume of the optic apparatus that received $80 \%$ of the prescribed dose was $<0.05 \mathrm{~cm}^{3}$, whereas the volume that received $50 \%$ of the dose was $<0.5 \mathrm{~cm}^{3}$. Therefore, the actual volume of the optic segment that received 5 Gy would be small relative to the total volume of the optic apparatus.

In the present study, we have shown that radiosurgery delivered with the CyberKnife is an effective adjuvant therapy after surgery for residual craniopharyngiomas. Tumor control or shrinkage without any neuroendocrine or visual complications was achieved in $10(91 \%)$ of 11 patients. We delivered a multisession treatment regimen, which minimized the risk to the optic apparatus and pituitary gland. Moreover, a nonisocentric treatment plan was used successfully, which improved dose homogeneity and thereby reduced dosing hotspots on structures such as the optic nerves and chiasm. None of the patients required additional hormonal therapy. Preservation of baseline visual function is supported by our previous work, which also showed that the risk of visual loss with multisession radiosurgery appears to be low for perioptic tumors.1,38 Radiation-induced optic neuropathy may take several years to develop, but it usually occurs within the first 24 months after irradiation. However, a limitation of our study is the relatively short follow-up period and small number of patients. Although none of the patients in the present study had worsening visual acuity or visual fields, definitive conclusions regarding the safety of multisession CyberKnife SRS cannot be reached. The selection of doses and number of sessions have also been derived empirically and from experience with other radiotherapy and frame-based radiosurgical procedures. Again, in the absence of Class 1 studies, the optimal dose and number of sessions for individual patients are still not known. In 1 case, cystic enlargement occurred after CyberKnife treatment. It is known that irradiation of cystic craniopharyngiomas may result in cystic enlargement, which does not represent tumor recurrence, and may later regress. ${ }^{8}$ The patient's symptoms remained stable, but it is important that these patients continue to undergo clinical and radiological follow-up and visual and neuroendocrine assessment as appropriate. A larger numbers of patients with longer follow-up periods are required to evaluate the safety and effectiveness of this treatment modality fully.

\section{Conclusions}

Craniopharyngioma is a benign tumor that frequently involves the eloquent structures of the sellar and suprasellar regions. The optimal treatment strategy for cranio- pharyngiomas remains controversial. However, due to the high surgical risk and tendency for recurrence in STR, an individualized multimodal treatment strategy must be used to optimize outcome. Radiotherapy has a definitive role both as an adjuvant therapy after primary STR and also as a primary treatment for recurrent disease. The multisession capability of the CyberKnife allows treatment of craniopharyngiomas adjacent to the optic nerve and is effective in tumor control and shrinkage while preserving the function of nearby structures, such as the optic apparatus and pituitary gland. The avoidance of the need for rigid head fixation is particularly advantageous in pediatric patients.

\section{Disclosure}

Dr. Adler is on the board of directors of Accuray, Inc., and Drs. Adler and Chang are both shareholders of Accuray, Inc.

\section{References}

1. Adler JR Jr, Gibbs IC, Puataweepong P, Chang SD: Visual field preservation after multisession cyberknife radiosurgery for perioptic lesions. Neurosurgery 59:244-254, 2006

2. Agha A, Sherlock M, Brennan S, O'Connor SA, O'Sullivan E, Rogers B, et al: Hypothalamic-pituitary dysfunction after irradiation of nonpituitary brain tumors in adults. J Clin Endocrinol Metab 90:6355-6360, 2005

3. Brada M, Ford D, Ashley S, Bliss JM, Crowley S, Mason M, et al: Risk of second brain tumor after conservative surgery and radiotherapy for pituitary adenoma. BMJ 304:1343-1346, 1992

4. Bunin GR, Surawicz TS, Witman PA, Preston-Martin S, Davis F, Bruner JM: The descriptive epidemiology of craniopharyngioma. J Neurosurg 89:547-551, 1998

5. Caldarelli M, di Rocco C, Papacci F, Colosimo C Jr: Management of recurrent craniopharyngioma. Acta Neurochir (Wien) 140: 447-454, 1998

6. Caldarelli M, Massimi L, Tamburrini G, Cappa M, Di Rocco C: Long-term results of the surgical treatment of craniopharyngioma: the experience at the Policlinico Gemelli, Catholic University, Rome. Childs Nerv Syst 21:747-757, 2005

7. Chiou SM, Lunsford LD, Niranjan A, Kondziolka D, Flickinger JC: Stereotactic radiosurgery of residual or recurrent craniopharyngioma, after surgery, with or without radiation therapy. Neuro Oncol 3:159-166, 2001

8. Constine LS, Randall SH, Rubin P, McDonald J: Craniopharyngiomas: fluctuation in cyst size following surgery and radiation therapy. Neurosurgery 24:53-59, 1989

9. Darzy KH, Shalet SM: Hypopituitarism after cranial irradiation. J Endocrinol Invest 28 (5 Suppl):78-87, 2005

10. Fahlbusch R, Honegger J, Paulus W, Huk W, Buchfelder M: Surgical treatment of craniopharyngiomas: experience with 168 patients. J Neurosurg 90:237-250, 1999

11. Fisher BJ, Gaspar LE, Noone B: Radiation therapy of pituitary adenoma: delayed sequelae. Radiology 187:843-846, 1993

12. Fisher PG, Jenab J, Gopldthwaite PT, Tihan T, Wharam MD, Foer $\mathrm{DR}$, et al: Outcomes and failure patterns in childhood craniopharyngiomas. Childs Nerv Syst 14:558-563, 1998

13. Girkin CA, Comey CH, Lunsford LD, Goodman ML, Kline LB: Radiation optic neuropathy after stereotactic radiosurgery. Ophthalmology 104:1634-1643, 1997

14. Gupta DK, Ojha BK, Sarkar C, Mahapatra AK, Sharma BS, Mehta VS: Recurrence in pediatric craniopharyngiomas: analysis of clinical and histological features. Childs Nerv Syst 22:50-55, 2006

15. Habrand JL, Ganry O, Couanet D, Rouxel V, Levy-Piedbois C, Pierre-Kahn A, et al: The role of radiation therapy in the management of craniopharyngioma: a 25-year experience and review of the literature. Int J Radiat Oncol Biol Phys 44:255-263, 1999

16. Haupt R, Magnani C, Pavanello M, Caruso S, Dama E, Garrè ML: 
Epidemiological aspects of craniopharyngioma. J Pediatr Endocrinol Metab 19 (1 Suppl):289-293, 2006

17. Hetelekidis S, Barnes PD, Tao ML, Fischer EG, Schneider L, Scott RM, et al: 20-year experience in childhood craniopharyngioma. Int J Radiat Oncol Biol Phys 27:189-195, 1993

18. Hoffman HJ, De Silva M, Humphreys RP, Drake JM, Smith ML, Blaser SI: Aggressive surgical management of craniopharyngiomas in children. J Neurosurg 76:47-52, 1992

19. Honegger J, Barocka A, Sadri B, Fahlbusch R: Neuropsychological results of craniopharyngioma surgery in adults: a prospective study. Surg Neurol 50:19-29, 1998

20. Honegger J, Buchfelder M, Fahlbusch R: Surgical treatment of craniopharyngiomas: endocrinological results. J Neurosurg 90: 251-257, 1999

21. Hoshi M, Hayashi T, Kagami H, Murase I, Nakatsukasa M: Late bilateral temporal lobe necrosis after conventional radiotherapy. Neurol Med Chir (Tokyo) 43:213-216, 2003

22. Isaac MA, Hahn SS, Kim JA, Bogart JA, Chung CT: Management of craniopharyngioma. Cancer J 7:516-520, 2001

23. Jose CC, Rajan B, Ashley S, Marsh H, Brada M: Radiotherapy for the treatment of recurrent craniopharyngioma. Clin Oncol ( $\mathbf{R}$ Coll Radiol) 4:287-289, 1992

24. Kalapurakal JA, Goldman S, Hsieh YC, Tomita T, Marymont $\mathrm{MH}$ : Clinical outcome in children with craniopharyngioma treated with primary surgery and radiotherapy deferred until relapse. Med Pediatr Oncol 40:214-218, 2003

25. Kalapurakal JA, Goldman S, Hsieh YC, Tomita T, Marymont MH: Clinical outcome in children with recurrent craniopharyngioma after primary surgery. Cancer J 6:388-393, 2000

26. Kalapurakal JA, Kepka A, Bista T, Goldman S, Tomita T, Marymont $\mathrm{MH}$ : Fractionated stereotactic radiotherapy for pediatric brain tumors: the Chicago children's experience. Childs Nerv Syst 16:296-303, 2000

27. Karavitaki N, Cudlip S, Adams CB, Wass JA: Craniopharyngiomas. Endocr Rev 27:371-397, 2006

28. Kobayashi T, Kida Y, Mori Y, Hasegawa T: Long-term results of gamma knife surgery for the treatment of craniopharyngioma in 98 consecutive cases. J Neurosurg 103 (6 Suppl):482-488, 2005

29. Kobayashi T, Tanaka T, Kida Y: Stereotactic gamma radiosurgery of craniopharyngiomas. Pediatr Neurosurg 21 (1 Suppl):69-74, 1994

30. Kramer S, Southard M, Mansfield CM: Radiotherapy in the management of craniopharyngiomas: further experiences and late results. AJR Radium Ther Nucl Med 103:44-52, 1968

31. Kuratsu J, Ushio Y: Epidemiological study of primary intracranial tumors in childhood. A population-based survey in Kumamoto Prefecture, Japan. Pediatr Neurosurg 25:240-247, 1996

32. Leber KA, Bergloff J, Pendl G: Dose-response tolerance of the visual pathways and cranial nerves of the cavernous sinus to stereotactic radiosurgery. J Neurosurg 88:43-50, 1998

33. McCollough WM, Marcus RB Jr, Rhoton AL Jr, Ballinger WE, Million RR: Long-term follow-up of radiotherapy for pituitary adenoma: the absence of late recurrence after greater than or equal to 4500 cGy. Int J Radiat Oncol Biol Phys 21:607-614, 1991

34. McCord MW, Buatti JM, Fennell EM, Mendenhall WM, Marcus RB Jr, Rhoton AL, et al: Radiotherapy for pituitary adenoma: long-term outcome and sequelae. Int J Radiat Oncol Biol Phys 39:437-444, 1997

35. Minamida Y, Mikami T, Hashi K, Houkin K, et al: Surgical management of the recurrence and regrowth of craniopharyngiomas. $\mathbf{J}$ Neurosurg 103:224-232, 2005

36. Moon SH, Kim IH, Park SW, Kim I, Hong S, Park CI, et al: Early adjuvant radiotherapy toward long-term survival and better quality of life for craniopharyngiomas - a study in single institute. Childs Nerv Syst 21:799-807, 2005

37. Movsas B, Movsas TZ, Steinberg SM, Okunieff P: Long-term visual changes following pituitary irradiation. Int J Radiat Oncol Biol Phys 33:599-605, 1995
38. Pham CJ, Chang SD, Gibbs IC, Jones P, Heilbrun MP, Adler JR Jr: Preliminary visual field preservation after staged CyberKnife radiosurgery for perioptic lesions. Neurosurgery 54:799-812, 2004

39. Rajan B, Ashley S, Gorman C, Jose CC, Horwich A, Bloom HJ, et al: Craniopharyngioma-long-term results following limited surgery and radiotherapy. Radiother Oncol 26:1-10, 1993

40. Rajan B, Ashley S, Thomas DG, Marsh H, Britton J, Brada M: Craniopharyngioma: improving outcome by early recognition and treatment of acute complications. Int J Radiat Oncol Biol Phys 37:517-521, 1997

41. Regine WF, Mohiuddin M, Kramer S: Long-term results of pediatric and adult craniopharyngiomas treated with combined surgery and radiation. Radiother Oncol 27:13-21, 1993

42. Sachs RK, Brenner DJ: Solid tumor risks after high doses of ionizing radiation. Proc Natl Acad Sci U S A 102:13040-13045, 2005

43. Schulz-Ertner D, Frank C, Herfarth KK, Rhein B, Wannenmacher M, Debus J: Fractionated stereotactic radiotherapy for craniopharyngiomas. Int J Radiat Oncol Biol Phys 54:1114-1120, 2002

44. Selch MT, DeSalles AA, Wade M, Lee SP, Solberg TD, Wallace $\mathrm{RE}$, et al: Initial clinical results of stereotactic radiotherapy for the treatment of craniopharyngiomas. Technol Cancer Res Treat 1: 51-59, 2002

45. Shi XE, Wu B, Fan T, Zhou ZQ, Zhang YL: Craniopharyngioma: surgical experience of 309 cases in China. Clin Neurol Neurosurg 110:151-159, 2007

46. Stripp DC, Maity A, Janss AJ, Belasco JB, Tochner ZA, Goldwein JW, et al: Surgery with or without radiation therapy in the management of craniopharyngiomas in children and young adults. Int J Radiat Oncol Biol Phys 58:714-720, 2004

47. Thompson D, Phipps K, Hayward R: Craniopharyngioma in childhood: our evidence-based approach to management. Childs Nerv Syst 21:660-668, 2005

48. Tomita T, Bowman RM: Craniopharyngiomas in children: surgical experience at Children's Memorial Hospital. Childs Nerv Syst 21:729-746, 2005

49. Tsang RW, Brierley JD, Panzarella T, Gospodarowicz MK, Sutcliffe SB, Simpson WJ: Radiation therapy for pituitary adenoma: treatment outcome and prognostic factors. Int J Radiat Oncol Biol Phys 30:557-565, 1994

50. Ulfarsson E, Lindquist C, Roberts M, Rähn T, Lindquist M, Thorén $\mathrm{M}$, et al: Gamma knife radiosurgery for craniopharyngiomas: long-term results in the first Swedish patients. J Neurosurg 97 (5 Suppl):613-622, 2002

51. Van Effenterre R, Boch AL: Craniopharyngioma in adults and children: a study of 122 surgical cases. J Neurosurg 97:3-11, 2002

52. Varlotto JM, Flickinger JC, Kondziolka D, Lunsford LD, Deutsch M: External beam irradiation of craniopharyngiomas: long-term analysis of tumor control and morbidity. Int J Radiat Oncol Biol Phys 54:492-499, 2002

53. Vinchon M, Dhellemmes P: Craniopharyngiomas in children: recurrence, reoperation and outcome. Childs Nerv Syst 24:211217, 2008

54. Yaşargil MG, Curcic M, Kis M, Siegenthaler G, Teddy PJ, Roth P: Total removal of craniopharyngiomas. Approaches and longterm results in 144 patients. J Neurosurg 73:3-11, 1990

55. Zuccaro G: Radical resection of craniopharyngioma. Childs Nerv Syst 21:679-690, 2005

Manuscript submitted January 16, 2008.

February 15, 2008.

Address correspondence to: Marco Lee, M.D., Ph.D., F.R.C.S., Stanford University Hospital, 300 Pasteur Drive, Stanford, California 94305. email: marcolee@ stanford.edu. 